\title{
PREOPERATIVE EMBOLIZATION OF INTRACRANIAL MENINGIOMA WITH HISTOACRYL THROUGH MIDDLE MENINGEAL ARTERY: THE EFFECT ON INTRAOPERATIVE BLOOD LOSS AND COMPLICATIONS RELATED TO THE PROCEDURES.
}

Seng Hong Koh ${ }^{1 *}$, Khairul Azmi Abd Kadir ${ }^{1}$, Fadhli Mohamed Sani ${ }^{1}$.

${ }^{1}$ Department of Biomedical Imaging, Faculty of Medicine, University of Malaya, Kuala Lumpur, Malaysia

*Corresponding author:

Dr. Seng Hong Koh, Department of Biomedical Imaging, Faculty of Medicine, University of Malaya, Kuala Lumpur, Malaysia.

DOI: https://doi.org/10.32896/tij.v1n1.1-11

Published: 30.06 .2021

\begin{abstract}
Introduction: This study aims to evaluate the effectiveness of preoperative embolization of intracranial meningioma using N-Butyl-2-Cyanoacrylate (Histoacryl) in reducing intraoperative blood loss and to assess the complications related to this procedure.

Materials and methods: This is a single-centered retrospective cross-sectional study of 106 patients with histologically proven meningioma underwent open surgical resection in University Malaya Medical Centre (UMMC) from $1^{\text {st }}$ of January 2010 till $31^{\text {st }}$ of May 2020. Out of the 106 samples, 29 of them underwent Histoacryl embolization prior to the surgery and 77 of them were subjected to surgery without preoperative embolization. The demographic data, mean comparison and correlation testing were performed using Statistical Package for the Social Sciences (SPSS).

Result: The majority of patients were female gender (68\%). Most of the tumour were WHO grade 1 meningioma (86\%). $48 \%$ of patients in the embolized group were transfused. Female gender had a longer duration of operation ( $280 \mathrm{~min}$ vs $234 \mathrm{~min}$ ) and required higher amount of blood transfusion (1.3pint vs 0.6 pint $)$ compared to male gender $(\mathrm{P}<0.05)$. No statistical significance was found in the mean intraoperative blood loss, duration of operation and amount of blood transfused between the embolized and non-embolized group $(\mathrm{P}>0.05)$. No post-embolization complication encountered in our centre. The meningo-opthalmic branch is seen in $4 \%$ of our study population.

Conclusion: Preoperative embolization of meningioma is a safe procedure with careful patient selection. No significant difference is observed in the intraoperative blood loss, duration of operation and amount of blood transfused between the embolized and the non-embolized group. However, we find that female has a significant longer duration of operation and requires higher amount of blood transfusion.
\end{abstract}

Keywords: Preoperative embolization, Intracranial meningioma, Histoacryl, Meningo-opthalmic branch.

\section{INTRODUCTION}

Preoperative embolization of meningioma is carried out as meningioma is a highly vascularized tumour with the aim to reduce intraoperative blood loss, reduce the need of blood transfusion and shorten the operative duration. Moreover, the middle meningeal artery which is a common feeder of this tumour has an intraosseous course which imposes risk of uncontrolled bleeding intraoperatively during resection (1). The risks involved in meningioma embolization include those related to the angiography procedure 
(contrast reaction, puncture site hematoma and vessel dissection) or more serious neurological complications (stroke, bleed and cranial nerve palsy due to injury of vasa nervorum). Other potential complications are scalp necrosis, permanent disability or death, which is very uncommon (2).

There is a wide range of embolic materials available in the market. Commonly used liquid embolic agent are N-butyl cyanoacrylate (Histoacryl) (3) and ethylene vinyl alcohol copolymer (Onyx) (4) while commonly used particulate embolic agents are polyvinyl alcohol (PVA) $(5,6)$ and tris-acryl gelatin microsphere (TAGM) $(5,7)$. The choice of embolic agent used is greatly depending on the operator preference and the anatomical consideration. Some studies show that liquid embolic material is more superior than particulate embolic material in preoperative embolization of meningioma as it simultaneously occludes the proximal and distal vessels. Therefore, the risk of intra-tumoral bleed from the collateral is lesser (8). It is also found that liquid embolic material reduces usage of contrast medium and when there is a single feeding vessel, it reduces the duration of embolization resulting in improved patient safety (9).

Histoacryl is a type of NBCA marketed by B. Braun (C). This tissue adhesive embolic agent polymerizes immediately upon contact with tissue fluid. Kominami et al reported that NBCA performs better as it can be delivered with lower injection pressure and can be used with a wider range of microcatheters. Besides, it enters feeding vessels of meningioma simultaneously upon injection and prevents intratumoral bleed. When in use with lipiodol, it becomes radio-opaque and real time observation of movement of NCBA into dangerous anastomoses is made possible. The recognized disadvantage of NBCA is reflux into the normal cerebral artery due to its proximal occlusion of the feeding vessel (3). However, patient may still benefit from this proximal occlusion and the risk of hemorrhage is lesser compared with particulate embolic material (10).

The purpose of this study is to evaluate the effectiveness of preoperative meningioma embolization using N-butyl cyanoacrylate (Histoacryl) in reducing intraoperative blood loss, to study the percentage of patient with ICA-ECA communication and to assess the complications related to the procedure at University Malaya
Medical Centre from year 2010 to 2020. This research is important and beneficial for us to study in depth about the safety profile of this embolic material and aid in counselling and management of meningioma patients in the future.

\section{MATERIAL AND METHODS Study design}

This is a single center, retro-prospective study on the effectiveness of preoperative embolization of meningioma using Histoacryl via the middle meningeal artery in University Malaya Medical Centre (UMMC). The intraoperative blood loss in meningioma patient embolized with Histoacryl was compared with patients who underwent open surgical resection of meningioma without preoperative embolization. Ethical approval was secured from the institutional Medical Ethic Committee (MECID No: 20287-8965).

This study received no financial support or funding. Retrospective screening of histologically confirmed meningioma patients with matching criteria who was diagnosed between $1^{\text {st }}$ January 2010 to $31^{\text {st }}$ May 2020 in UMMC were retrieved using the Laboratory Information System (LIS). The other data parameters were then traced from the Hospital Information System (HIS) and the Radiology Information System (RIS).

\section{Study subject}

The retrospective patient cohort was selected by reviewing all histopathology reports in UMMC from $1^{\text {st }}$ January 2010 to $31^{\text {st }}$ May 2020 and only patient with histologically proven meningioma will be selected. The histological findings and WHO grading of meningioma were traced from UMMC Laboratory Information System (LIS). The clinical data and operative notes of these patients were assessed via the UMMC Hospital Information System (HIS) portal. The imaging series, imaging findings, embolic agents used as well as complication during the procedure were gathered from UMMC Radiology Information System. (RIS).

Only cases with diagnosis of intracranial meningioma embolized with Histoacryl and complete clinical data were sampled. A total of 106 patients were found to be suitable to be recruited into the study. A total of 37 patients were excluded as there were incomplete clinical and operative details. Majority of those patients had no 
documented intraoperative blood loss. 9 patients who were embolized with Polyvinyl alcohol (PVA) and/or microcoils were excluded from this study as well.

\section{Inclusion criteria}

- All histologically proven intracranial meningioma patients from $1^{\text {st }}$ of January 2010 until $31^{\text {st }}$ of May 2020.

\section{Exclusion criteria}

- Patient with intracranial meningioma embolized with non-Histoacryl embolic agent.

- Patient with incomplete clinical or operative data.

\section{Data parameters and processing}

Microsoft Excel is utilized as data collection sheet. The data parameters include the followings:

- Medical Registration Number (MRN)

- Age

- Gender

- Tumour volume

- Presence of meningo-opthalmic anastomosis

- Embolic agent used

- Complication of embolization *

- Intraoperative blood loss ${ }^{\wedge}$

- Duration of operation

- Intraoperative and immediate post-operative packed cell transfusion \#

- Histology Reporting date

- Histology grading of meningioma (WHO grading)

*Complication of embolization is traced from the procedure note in RIS and follow up till the period of surgery from HIS. In our center, the open surgical resection is usually scheduled on the day after the meningioma embolization.

^Intraoperative blood loss is traced from the general anaesthesia note and represent a rough estimation by our trained anaesthetist.

\# Amount of packed cell transfusion is traced from the general anaesthesia entry up to the period when patient was discharged from recovery bay to neuro ICU.

The data were then analyzed to review the patient demographic distribution and a series of statistical testing were performed using S.P.S.S. software for Windows (Version 25.0, 2017, I.B.M. Corp, Armonk, NY).

\section{Patient selection for meningioma embolization}

The patient selection for preoperative embolization of meningioma in our centre was made by the treating neurosurgeon on case-on-case basis. It was mainly depending on the clinical judgement of the referring surgeon.

\section{Statistical analysis and data interpretation}

Data was subjected to normality check using using S.P.S.S. software for Windows (Version 25.0, 2017, I.B.M. Corp, Armonk, NY). Normality testing was performed using a Shapiro-Wilk test. In this study, Mann-Whitney U test was applied to compare differences between embolized and nonembolized groups of patients as the data was not normally distributed. Spearman correlation test was performed to analyse the correlations between my variables.

\section{- Shapiro Wilk test}

- $\quad$ Check for normality of the variables.

- Mann-Whitney U test

- To compare the mean difference between embolized and non-embolized groups with their intraoperative blood loss, OT time and amount of blood transfused.

- $\quad$ To compare the mean difference between gender with their intraoperative blood loss, OT time and amount of blood transfused.

- $\quad$ to compare the mean difference between patient embolized with Histoacyl and nonHistoacryl with their intraoperative blood loss, OT time and amount of blood transfused.

\section{- Spearman correlation}

- To analyse the relationship between the dependent variables (intraoperative blood loss, OT time and amount of blood transfused).

- To analyse the relationship between age, tumour volume, intraoperative blood loss, OT time and amount of blood transfused. 
Steps in embolization of intracranial meningioma using Histoacryl in our centre.

This procedure was done under aseptic technique with local anaesthesia coverage. Via the femoral approach, the femoral artery was punctured and a $6 \mathrm{~F}$ arterial sheath was introduced. A $5 \mathrm{~F}$ vertebral catheter was then advanced into the aortic arch followed by diagnostic angiography of the right and left internal carotid, external carotid and vertebral arteries. The meningioma blood supply was then identified. Possible ICA-ECA anastomosis was evaluated. Selective catheterization of the middle meningeal artery was carried out under fluoroscopic guidance using microcatheter. Embolization of the intracranial meningioma was performed with premixed $0.5 \mathrm{mls}$ Histoacryl (25\% concentration) and $1.5 \mathrm{mls}$ of lipiodol. Special care was given to prevent reflux of Histoacryl to the supplying main vessel. An immediate post embolization cerebral angiography was performed to assess the outcome of the embolization as well as the possible complication.

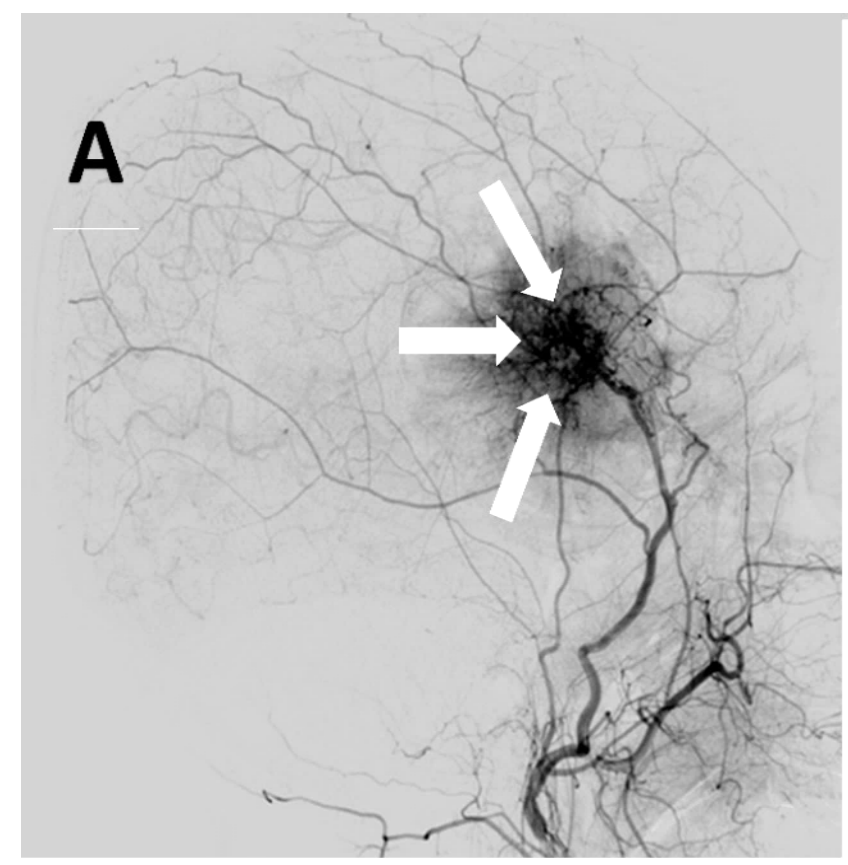

B

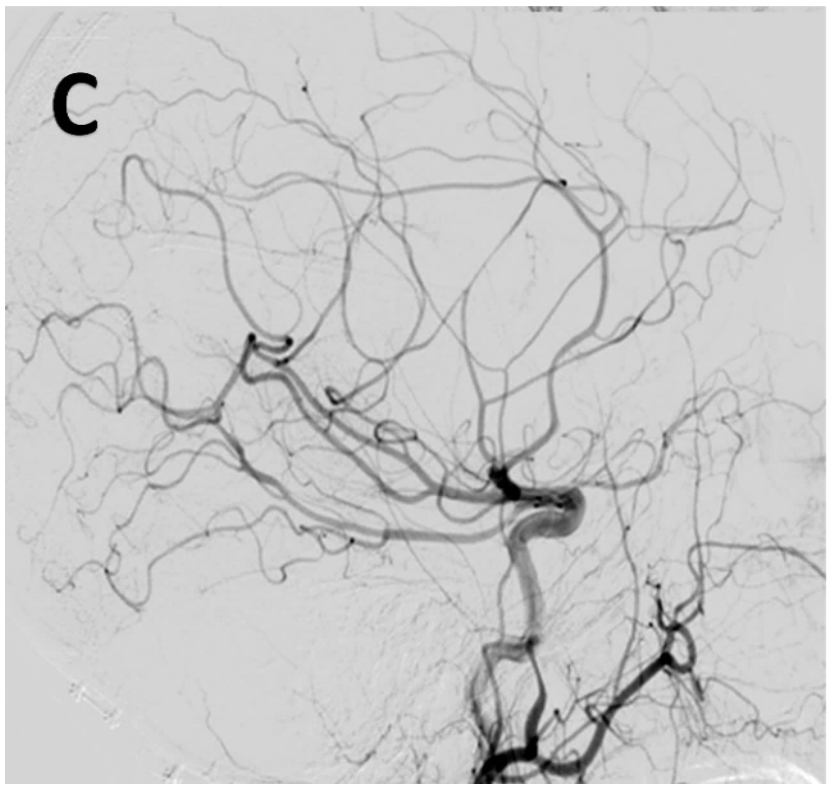

D

Figure 1: Preembolization cerebral angiogram of left external carotid artery in lateral view(Figure A) and AP view(Figure B) showing left parieto-temporal meningioma. Tumoural blush (white arrows) seen arising from the middle meningeal branch of the left external carotid artery. Postembolization (Figure $\mathrm{C}$ and $\mathrm{D}$ ) shows complete devascularization of the meningioma. 


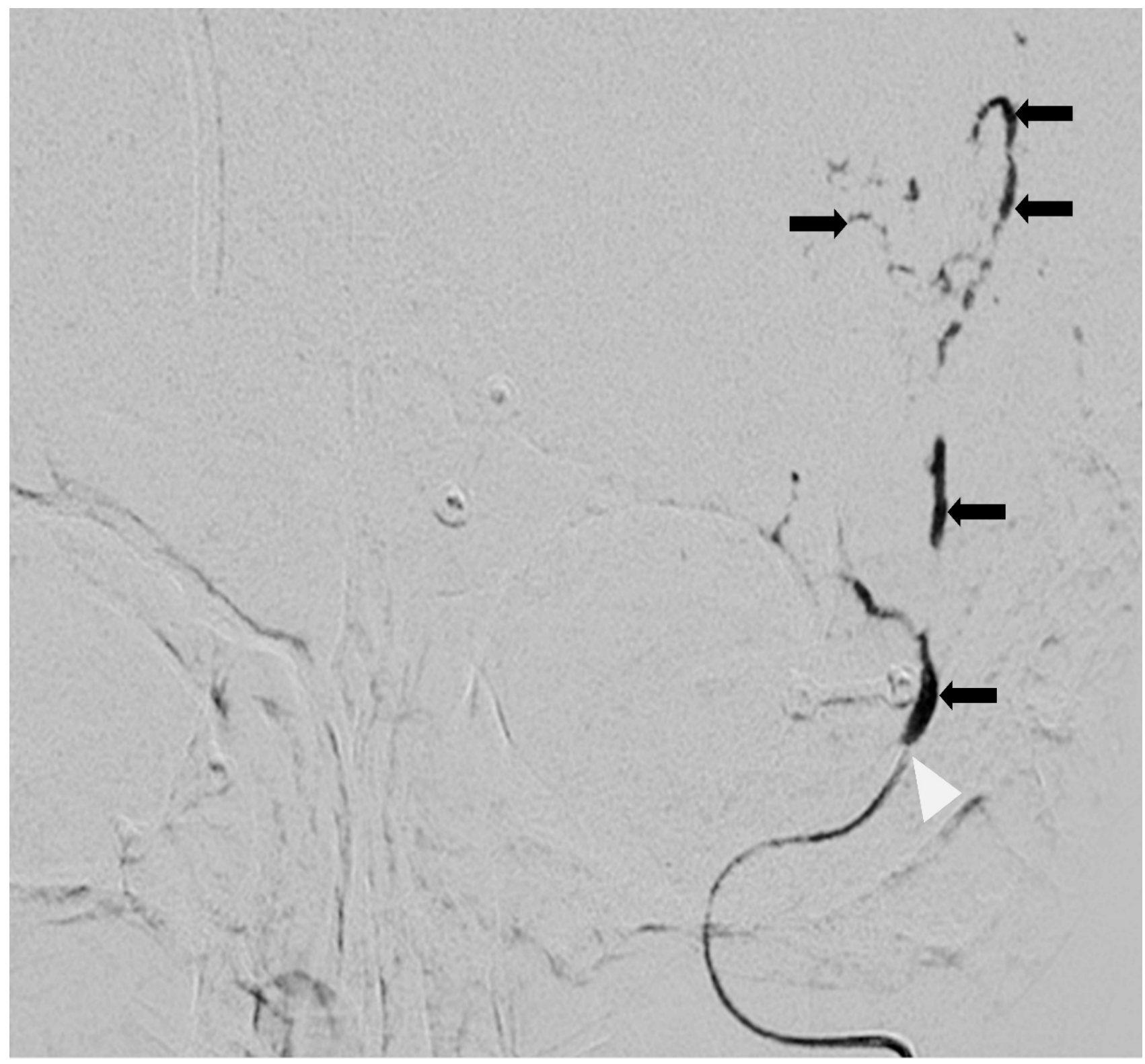

Figure 2: Embolization with Histoacryl through the left middle meningeal artery under fluoroscopic guidance (White arrowhead showing tip of microcatheter; Black arrows shows mixure of Histoacryl with Lipiodol).

RESULTS

Demographic distribution

Gender

\begin{tabular}{|l|l|l|l|}
\hline & Embolized & Non-embolized & Total patient \\
\hline Male & 9 & 25 & 34 \\
\hline Female & 20 & 52 & 72 \\
\hline & 29 & 77 & 106 \\
\hline
\end{tabular}

Table 1: Descriptive statistics on gender in embolized and non-embolized group 
Female gender comprised the majority with a total number of 72 patients $(67.9 \%)$. Out of the 72 female patient, $20(27.8 \%)$ of them were embolized prior to open surgical excision whereas 52 of female patients were subjected to surgery without prior embolization. About half of the patients who were diagnosed with intracranial meningioma fell in the age group category of 51 to 70 years old, which comprised of $50.9 \%$ of total patient with the mean age of $58.8 \pm 13.5$ years old. Most of the intracranial meningioma $(\mathrm{n}=74,70 \%)$ had tumour volume less than $50 \mathrm{mls}$. $85.7 \%$ of meningioma cases in the tumour volume category of $>100 \mathrm{mls}$ compared to $13.5 \%$ of meningioma cases in the tumour volume category of $<50 \mathrm{mls}$ were embolized. The tumour volume distribution was comparable between the two groups with $61 \%$ $(n=21)$ of male and $63 \%(n=46)$ of female fall in tumour volume category of $<50 \mathrm{mls} .26 \%(\mathrm{n}=9)$ of male and $24 \%(n=18)$ of female fall in tumour volume category of $50-100 \mathrm{mls} .11 \%(\mathrm{n}=4)$ of male and $12 \%(n=9)$ of female fall in tumour volume category of $>100 \mathrm{mls}$. The mean of tumour volume in female is $44.1 \mathrm{mls}$ and $52.5 \mathrm{mls}$ in male. Majority of the intracranial meningioma were WHO grade 1 tumor which comprised of $86 \%$ of total cases.

\begin{tabular}{|l|c|c|c|}
\hline & Embolized & Non-Embolized & Two- sided P value \\
\hline Mean Blood Loss(ml) & $627.5 \pm 356.2$ & $774.6 \pm 595.1$ & 0.39 \\
\hline Mean OT time(min) & $240.5 \pm 109.9$ & $275.1 \pm 132.1$ & 0.22 \\
\hline Mean Blood Transufsion (pint) & $1.1 \pm 1.3$ & $1.1 \pm 1.6$ & 0.58 \\
\hline
\end{tabular}

${ }^{*}$ statistical significance at $P<0.05$

Table 2: Mean comparison of intraoperative blood loss, duration of operation and amount of blood transfused in embolized $(n=29)$ and non-embolized $(n=77)$ group

\begin{tabular}{|l|c|c|c|}
\hline & Male & Female & Two- sided P value \\
\hline Mean Blood Loss $(\mathrm{ml})$ & $583.8 \pm 295.3$ & $805.6 \pm 615.7$ & 0.21 \\
\hline Mean OT time(min) & $234.7 \pm 141.1$ & $280.2 \pm 117.7$ & $0.03 *$ \\
\hline Mean Blood Transufsion (pint) & $0.6 \pm 0.9$ & $1.3 \pm 1.7$ & $0.02 *$ \\
\hline
\end{tabular}

$*_{\text {statistical significance at } P<0.05}$

Table 3: Mean comparison of intraoperative blood loss, duration of operation and amount of blood transfused between male $(n=34)$ and female $(n=72)$ gender.

No significant difference between embolized and non-embolized group in intraoperative blood loss, operation duration and amount of blood transfused. The mean operation duration is longer (280min vs
$235 \mathrm{~min}$ ) with greater amount of blood transfused (1.3pint vs 0.6 pint) with $P$ value of 0.03 and 0.02 respectively. 


\begin{tabular}{|c|c|c|c|c|}
\hline \multicolumn{5}{|c|}{ SPEARMAN CORRELATION COEFFICIENTS, N = 106} \\
\hline & & $\begin{array}{c}\text { Duration of } \\
\text { operation }\end{array}$ & $\begin{array}{l}\text { Intraoperative } \\
\text { blood loss }\end{array}$ & $\begin{array}{l}\text { Amount of blood } \\
\text { transfused }\end{array}$ \\
\hline \multirow{2}{*}{$\begin{array}{l}\text { Duration of } \\
\text { operation }\end{array}$} & $\begin{array}{l}\text { Pearson } \\
\text { correlation, } r\end{array}$ & - & 0.41 & 0.39 \\
\hline & $\mathrm{P}$ value & - & $<.0001 *$ & $<0.001^{*}$ \\
\hline \multirow{2}{*}{$\begin{array}{l}\text { Intraoperative } \\
\text { blood loss }\end{array}$} & $\begin{array}{l}\text { Pearson } \\
\text { correlation, } r\end{array}$ & 0.41 & - & 0.81 \\
\hline & $\mathrm{P}$ value & $<0.001 *$ & & $<0.001^{*}$ \\
\hline \multirow{2}{*}{$\begin{array}{l}\text { Amount of blood } \\
\text { transfused }\end{array}$} & $\begin{array}{l}\text { Pearson } \\
\text { correlation, } r\end{array}$ & 0.39 & 0.81 & - \\
\hline & $\mathrm{P}$ value & $<0.001 *$ & $<0.001 *$ & \\
\hline
\end{tabular}

*Significant difference at $P \leq 0.05$

Table 4: Correlations between duration of operation, blood loss and amount of blood transfused.

The duration of operation, intraoperative blood loss and amount of blood transfused were positively correlated and were statistically significant $(\mathrm{p}<0.001)$ with strong correlation seen between the intraoperative blood loss and amount of blood transfused $(\mathrm{r}=0.81)$.

\section{SPEARMAN CORRELATION COEFFICIENTS, $\mathrm{N}=29$}

\begin{tabular}{|c|c|c|c|c|c|}
\hline & & $\begin{array}{c}\text { Duration of } \\
\text { operation }\end{array}$ & $\begin{array}{l}\text { Intraoperative } \\
\text { blood loss }\end{array}$ & $\begin{array}{l}\text { Amount of blood } \\
\text { transfused }\end{array}$ & Age \\
\hline \multirow{2}{*}{ Age } & $\begin{array}{l}\text { Pearson } \\
\text { correlation, } r\end{array}$ & -0.14 & -0.16 & -0.09 & \multirow[t]{2}{*}{-} \\
\hline & $\mathrm{P}$ value & 0.13 & 0.09 & 0.32 & \\
\hline \multirow{2}{*}{$\begin{array}{l}\text { Tumour } \\
\text { volume }\end{array}$} & $\begin{array}{l}\text { Pearson } \\
\text { correlation, } r\end{array}$ & 0.06 & 0.31 & 0.29 & 0.18 \\
\hline & $P$ value & 0.50 & $0.00009 *$ & $0.0021 *$ & 0.05 \\
\hline
\end{tabular}

*Significant difference at $P \leq 0.05$

Table 5: Correlations between age, tumour volume, duration of operation, intraoperative blood loss and amount of blood transfused in patient embolized with Histoacryl.

Tumour volume had a weak positive correlation with intraoperative blood loss and amount of blood transfused $(\mathrm{r}=0.31$ and $\mathrm{r}=0.29)$ in patient embolized with Histoacryl and they were statistically significant $(\mathrm{p}<0.05)$. Age had no correlation with tumour volume, intraoperative blood loss and amount of blood transfused.

\section{Complication of embolization.}

There was no complication reported in all our patients during or post-procedural period when we followed up our patient until the period, they went in for their open brain surgery.

Prevalence of meningo-opthalmic anastomosis in patient diagnosed with meningioma.

There were in total 48 patients underwent cerebral angiogram examination in this study. Meningoopthalmic branch was found in 2 out of 48 patients which translated to $4 \%$ of patient. 


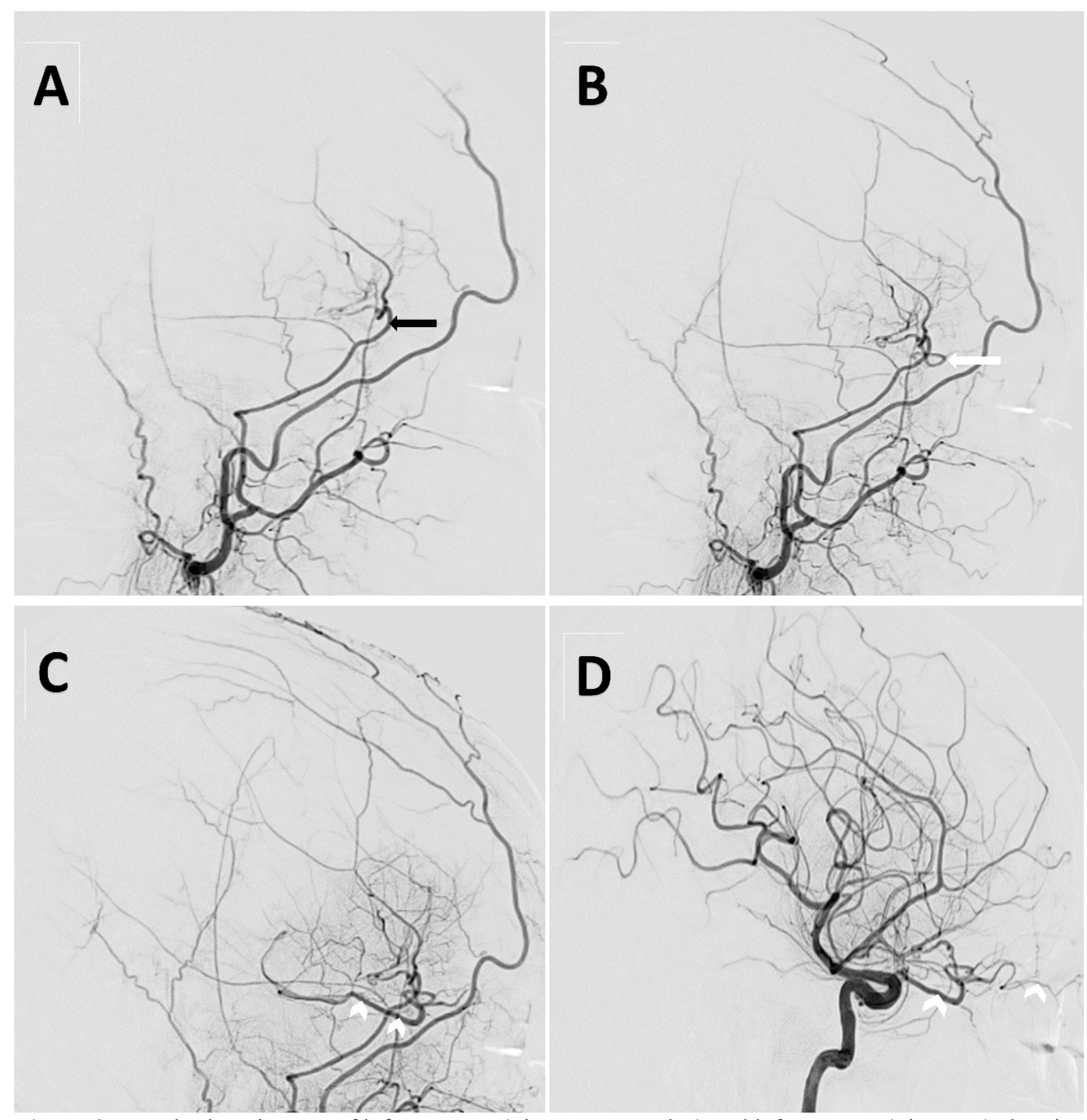

Figure 3: Cerebral angiogram of left ECA run (Figure A, B and C) and left ICA run (Figure D) showing the meningo-opthalmic anastomosis. Black arrow in A pointing at the middle meningeal artery. White arrow in B pointing at the meningo-opthalmic anastomosis. White arrowheads in $\mathrm{C}$ and $\mathrm{D}$ showing the left ophthalmic artery.

\section{DISCUSSION}

Preoperative embolization is a well-established adjuvant procedure in the management of intracranial meningioma. Out of the 106 cases that were sampled, only $27 \%$ of cases were embolized. The rate of embolization is lower compared to some studies carried out in other centers ranging from $37 \%$ to $44 \%(11,12)$. The lower embolization

rate in our center is due to more stringent selection of patients in embolization. Only arterial feeders by middle meningeal artery from external carotid artery will be embolized in this centre as embolization of pial or dural feeders from internal carotid artery carries higher ischemic complications (10). Moreover, middle meningeal 
artery which is a branch of maxillary artery of external carotid artery has a intraosseous course when it passes through foramen spinosum (1) and intraoperative manual compression of this artery is not possible if bleeding occurs.

Approximately $70 \%$ of intracranial meningioma cases have tumour volume of less than $50 \mathrm{mls}$. Majority of the patients are female accounting for $68 \%$ of total study sample. About half of the cases $(51 \%)$ fall in the age group of 51 to 70 years of age and as many as $86 \%$ of the cases are WHO grade 1 tumour. These findings are consistent with the studies done by other researchers $(2,10,11)$.

Most of the intracranial meningioma in this study has tumour volume of less than $50 \mathrm{mls}$. The percentage of embolized tumor is higher with increasing tumour volume. This can be explained by the tendency of neurosurgeon sending patients with larger tumour size for preoperative embolization aiming for devascularization of the tumour, an adjuvant therapy prior to surgical excision which is consistent with published paper by Dubel et al (2).

There are contradicting results in few studies done on preoperative embolization of meningioma. A study done by Dean et al shows there is significant reduction in intraoperative blood loss in the embolized group while Raper et al found that the intraoperative blood loss is significantly higher in the embolized group (11, 13). Bendszus et al reported that the mean intraoperative blood loss did not differ significantly and there is no significant difference between the two groups (14). In our study, the mean intraoperative blood loss in the embolized group is $19 \%$ lower than the non-embolized group $(628 \mathrm{mls}$ vs $775 \mathrm{mls}$ ), however it is not statistically significant $(\mathrm{P}>0.05)$ which could be attributed by the limitation of small sample size.

No significant difference between embolized and non-embolized cases in regards with their mean operation duration or amount of blood transfused. These findings were similar with few published papers where they also found that no significant difference in the operation duration or amount of blood transfused between the embolized and non-embolized group $(5,11,12)$.

In this study, there is significant difference in the mean operation duration between gender, with longer operation seen in females than in males (280 min vs $235 \mathrm{~min})(\mathrm{P}<0.05)$. Besides, females require higher amount of blood transfusion $(\mathrm{P}<0.05)$. The distribution of tumour volume and rate of embolization are however comparable among females and males in this study. The mean tumour volume in male is higher than female $(52.5 \mathrm{ml}$ vs $44.1 \mathrm{mls})$. Thus, eliminating the possibility of larger tumour size or unequal distribution of patient receiving embolization in these two groups resulting in the difference in the operation duration and amount of blood needed. No explanation is found on any published paper to date. These findings need to be confirmed in a larger study. With this piece of information, counselling can be done more effectively with better preparation of blood product for female patients prior to surgery. Rajagopalan et al found that female is an independent risk factor for intraoperative blood loss (15). Although the mean intraoperative blood loss in female gender is higher compared to male in this study ( $806 \mathrm{mls}$ vs $584 \mathrm{mls}$ ) but it is not statistically significant $(\mathrm{P}>0.05)$. This may be due to the limitation of small sample study. In another study done by Raper et al, they found out that male has a mean intraoperative blood loss instead (11).

Strong correlation seen between the intraoperative blood loss and the amount of blood transfused $(\mathrm{r}=0.81)$. Thus, reduction in intraoperative blood loss will result in reduction in amount of blood transfused reducing blood transfusion related complications. In addition, correlation between age, tumour volume and the dependent variables were analysed in patient embolized with Histoacryl undergone open surgical resection. Positive correlation found between tumour volume, intraoperative blood loss and amount of blood transfused and they are statistically significant $(\mathrm{p}<0.05)$. Larger tumour volume results in higher intraoperative blood loss, thus needing larger amount of blood transfusion $(16,17)$. Age on the other hand has no correlation with tumour volume, intraoperative blood loss and amount of blood transfused.

Study of the vascular supply is done carefully during the pre-embolization cerebral angiogram to determine whether there is abnormal ICA-ECA anastomosis particularly the meningoopthalmic anastomosis as embolization of this vessel can cause blindness (2). It is found that only $4 \%$ of our study population has this abnormal communication and all of them were not embolized due to the risk stated above. This is higher than the 
prelavence $(1.4 \%)$ found in other centre reviewing the anatomical variant of ophthalmic artery in 1655 patients (18).

There is no reported complication in our patients post embolization. This is due to the measures taken only to embolized through the middle meningeal artery feeders and the usage of liquid embolic agent with proven safety profile. Special care is also taken by our neurointerventional radiologist not to embolize the middle meningeal artery when there is abnormal ICA-ECA anastomosis particularly the meningoopthalmic branch. Feeders from the ICA branches will not be embolized as the risk is higher and the benefit is limited (19). It was reported that the complication rate of preoperative embolization of intracranial embolization ranges from $0 \%$ to $8.3 \%$ (2). With all the measures taken, the complication rate for meningioma embolization is kept at $0 \%$.

\section{REFERENCE}

1. Natali AL, Reddy V, Leo JT. Neuroanatomy, Middle Meningeal Arteries. StatPearls [Internet]. 2020.

2. Dubel GJ, Ahn SH, Soares GM. Contemporary endovascular embolotherapy for meningioma. Semin Intervent Radiol. 2013;30(3):263-77.

3. Kominami S, Watanabe A, Suzuki M, Mizunari T, Kobayashi S, Teramoto A. Preoperative embolization of meningiomas with N-butyl cyanoacrylate. Interventional Neuroradiology. 2012;18(2):133-9.

4. Trivelatto F, Nakiri G, Manisor M, Riva R, Al-Khawaldeh M, Kessler I, et al.

Preoperative onyx embolization of meningiomas fed by the ophthalmic artery: a case series. American journal of neuroradiology. 2011;32(9):1762-6.

5. Bendszus M, Klein R, Burger R, WarmuthMetz M, Hofmann E, Solymosi L. Efficacy of trisacryl gelatin microspheres versus polyvinyl alcohol particles in the preoperative embolization of meningiomas. American Journal of Neuroradiology. 2000;21(2):25561.

6. Carli D, Sluzewski M, Beute G, Van Rooij W. Complications of particle embolization of meningiomas: frequency, risk factors, and

\section{CONCLUSION}

Preoperative embolization of meningioma has been in practice for approximately 40 years. Our study has shown that there is no significant difference in the intraoperative blood loss, duration of operation and amount of blood transfused between the embolized and the non-embolized group using Histoacryl via the middle meningeal artery. Female has a significant longer duration of operation and requires higher amount of blood transfusion. Careful selection of patients and individual assessment should therefore be performed prior to subjecting patient for this procedure. It is important to note that this procedure is relatively safe with no complication encountered in our centre

outcome. American journal of neuroradiology. 2010;31(1):152-4.

7. Rodiek S, Stölzle A, Lumenta CB. Preoperative embolization of intracranial meningiomas with Embosphere ${ }^{\circledR}$ microspheres. min-Minimally Invasive Neurosurgery. 2004;47(05):299-305.

8. Shah A, Choudhri O, Jung H, Li G. Preoperative endovascular embolization of meningiomas: update on therapeutic options. Neurosurgical focus. 2015;38(3):E7.

9. Wang H-H, Luo C-B, Guo W-Y, Wu H-M, Lirng J-F, Wong T-T, et al. Preoperative embolization of hypervascular pediatric brain tumors: evaluation of technical safety and outcome. Child's Nervous System. 2013;29(11):2043-9.

10. Shah A, Choudhri O, Jung H, Li G. Preoperative endovascular embolization of meningiomas: update on therapeutic options. Neurosurg Focus. 2015;38(3):E7.

11. Raper DM, Starke RM, Henderson F, Jr., Ding D, Simon S, Evans AJ, et al. Preoperative embolization of intracranial meningiomas: efficacy, technical considerations, and complications. AJNR Am J Neuroradiol. 2014;35(9):1798-804.

12. Pedicelli A, Danieli L, Iacobucci M, Visconti E, D'Argento F, Colosimo C, editors. 
Preoperative embolisation of meningiomas: analysis of a single-centre experience 2015: European Congress of Radiology-ECR 2015.

13. Dean BL, Flom RA, Wallace RC, Khayata MH, Obuchowski NA, Hodak JA, et al. Efficacy of endovascular treatment of meningiomas: evaluation with matched samples. American Journal of Neuroradiology. 1994;15(9):1675-80.

14. Bendszus M, Rao G, Burger R, Schaller C, Scheinemann K, Warmuth-Metz M, et al. Is there a benefit of preoperative meningioma embolization? Neurosurgery. 2000;47(6):1306-12.

15. Rajagopalan V, Chouhan RS, Pandia MP, Lamsal R, Rath GP. Effect of intraoperative blood loss on perioperative complications and neurological outcome in adult patients undergoing elective brain tumor surgery. Journal of neurosciences in rural practice. 2019;10(4):631.

16. Hsu S-Y, Huang Y-H. Characterization and prognostic implications of significant blood loss during intracranial meningioma surgery. TRANSLATIONAL CANCER RESEARCH. 2016;5(6):797-804.

17. Lagman C, Ong V, Nguyen T, Alkhalid Y, Sheppard JP, Romiyo P, et al. The Meningioma Vascularity Index: a volumetric analysis of flow voids to predict intraoperative blood loss in nonembolized meningiomas. Journal of neurosurgery. 2018;130(5):1547-52.

18. Uchino A, Saito N, Takahashi M, Kozawa E, Mizukoshi W, Nakajima R, et al. Persistent dorsal ophthalmic artery and ophthalmic artery arising from the middle meningeal artery diagnosed by MR angiography at $3 \mathrm{~T}$. Surgical and Radiologic Anatomy. 2013;35(9):775-82.

19. Fang QR, He XY, Li XF, Zhang X, Chen M, Li H, et al. Comparative efficacy of Glubran and polyvinyl-alcohol particles in the embolization of meningiomas. Int J Neurosci. 2016;126(12):1112-9. 